\title{
Quality of care with telemedicine for medical assistance in dying eligibility assessments: a mixed-methods study
}

\author{
Stephanie Dion MHA, Ellen Wiebe MD, Michaela Kelly BASc
}

\section{Abstract}

Background: To facilitate access to medical assistance in dying (MAiD) in British Columbia, telemedicine has been used for eligibility assessments. This research explored the impacts of using telemedicine on quality of care.

Methods: This mixed-methods study consisted of data from $3 \mathrm{BC}$ health authorities and semistructured interviews with a patient, support persons, providers and administrators about the use of telemedicine for MAiD eligibility assessment. Interviews were conducted by telephone, video meeting or email between June and November 2018. We analyzed the quantitative data using descriptive statistics. We categorized the qualitative data using the 7 dimensions of the BC Health Quality Matrix and then analyzed them qualitatively with abductive coding.

Results: Twenty-one participants ( $8 \mathrm{MAiD}$ assessors, 1 patient, 7 support persons of patients and 5 MAiD administrators) were interviewed. Telemedicine for MAiD eligibility assessments was highly acceptable to the support persons and patient and to most assessors and administrators. Assessors expressed challenges with empathy, eye contact, nonverbal communication and missing contextual factors. Participants described which patients were appropriate and which were not. Telemedicine improved access and equity for the patients who received this service. It was perceived as an effective and efficient way to perform eligibility assessments. Concerns were expressed by assessors and administrators, but not by the patient or support persons, about confidentiality. Opinions varied on the requirement for a regulated health care professional to be in physical attendance with the patient to act as a witness.

Interpretation: Quality of care can be achieved with telemedicine for MAiD eligibility assessments for specific situations and patients, and this modality has the potential to expand access to MAiD. Updated clinical and administrative policies are needed to address barriers to telemedicine access and to best support patients and assessors using this technology.

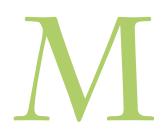
edical assistance in dying (MAiD) "occurs when an authorized doctor or nurse practitioner provides or administers medication that intentionally brings about a person's death, at that person's request." It has been legal in Canada since 2016. British Columbia has the highest proportion of medically assisted deaths in Canada, ${ }^{2}$ but access is still problematic. ${ }^{3-5}$ To qualify for MAiD, patients must be in an advanced state of decline in capacity, with reasonably foreseeable natural death; ${ }^{6}$ they are rarely in a condition to travel. In BC, "one of the medical assessors, but not both, may provide their assessment by telemedicine provided that, during the telemedicine assessment, another regulated health professional is in physical attendance with the patient to act as a witness to the assessment."

Telemedicine use is expanding in $\mathrm{BC} ;{ }^{8}$ it has been used in other areas of medicine effectively to help improve access., ${ }^{9,10}$ In this research, we explored the impacts of using telemedicine for MAiD eligibility assessments on quality of care from the perspective of patients, support persons, assessors and administrators involved in the MAiD process in $\mathrm{BC}$, addressing the question: Can quality of care be met with the use of telemedicine for MAiD eligibility assessments?

\section{Methods}

\section{Setting and participants}

This mixed-method study, which involved a convergent design, consisted of demographic and qualitative data obtained from semistructured interviews with patients, support persons, assessors and MAiD administrators who were involved with the use of telemedicine for MAiD eligibility assessments in BC. To assist with interpretation of the

\section{Competing interests: None declared.}

This article has been peer reviewed.

Correspondence to: Ellen Wiebe, ellenwiebe@gmail.com

CMAJ Open 2019. DOI:10.9778/cmajo.20190111 
qualitative data, we obtained quantitative information on the proportion of telemedicine assessments by surveying BC health authorities. The survey was sent via email to MAiD coordinators at 5 geographic/local health authorities offering MAiD care coordination services in April 2019 (as of that date, the First Nations Health Authority did not offer MAiD care coordination services and was not included in the survey). All interviews were conducted between June and November 2018 by 1 researcher (S.D.) by telephone or video meeting (using GoToMeeting); participants wishing to answer questions via email were provided with that option. The interviews were audiorecorded and transcribed (M.K.), and any identifying features were removed. To recruit participants, we sent an invitation letter and a written consent form via email to contacts of a medical clinic providing MAiD services in Vancouver who had been involved with the use of telemedicine for an eligibility assessment. Participants provided verbal (audiorecorded) or written consent or both.

\section{Interview guide}

The interview guide (Appendix 1, available at www. cmajopen.ca/content/7/4/E721/suppl/DC1) was developed with the BC Health Quality Matrix ${ }^{11}$ and included closed and open-ended questions. This framework, which comprises 7 dimensions of quality (Appendix 2, available at www. cmajopen.ca/content/7/4/E721/suppl/DC1), provides a common language for defining the quality of care and has been used by the BC Ministry of Health in setting priorities for the BC health care system. ${ }^{12}$ Participants were asked to provide insight about these dimensions according to their specific role and perspective. Experience with computers, the Internet and telemedicine was measured on a 5 -point Likert scale from 1 (no experience) to 5 (highly experienced), and satisfaction with telemedicine was measured on a 5-point Likert scale from 1 (highly dissatisfied) to 5 (highly satisfied). Two researchers from the field (E.W. and M.K.) reviewed the interview guide and provided feedback to ensure content validity. An iterative process was used; questions evolved with time and new perspectives, and the interview guide was modified accordingly.

\section{Data analysis}

We used Dedoose, a Web application for mixed-method research (www.dedoose.com), to facilitate interview analysis. We analyzed the quantitative data using descriptive statistics and processed the qualitative data using principles of a phenomenology theoretical framework. ${ }^{13}$ We categorized the qualitative data using the 7 dimensions of the BC Health Quality Matrix ${ }^{14}$ and then analyzed them abductively, first looking at the whole and then coding for themes. Three researchers (S.D., M.K. [master's candidates during the study] and E.W. [an experienced qualitative researcher]) met regularly to discuss coding and reach consensus on themes.

\section{Ethics approval}

Approval was obtained from the University of British Columbia Behavioural Research Ethics Board.

\section{Results}

Three BC health authorities provided data about the use of telemedicine for MAiD assessments (Table 1), a response rate of $50 \%$. A total of $0.3 \%-5.7 \%$ of all assessments were done by telemedicine.

Of the 24 people invited to participate, 21 (8 MAiD assessors, 1 patient, 7 support persons of patients and 5 MAiD administrators) (88\%) consented. Fourteen of the 21 agreed to be interviewed by telephone and 4 by video-conference, and 3 preferred to provide answers via email. The average interview duration was 30 minutes.

Table 2 provides the participants' demographic data, Table 3 provides an overview of their perception, experience and satisfaction regarding telemedicine, and Table 4 presents the types of devices, software and location used. Participants came from both urban or rural areas. The support persons and the patient had limited experience with telemedicine, whereas the assessors were somewhat experienced with telemedicine. A variety of devices and software were used for the consultations, which were conducted at home or through health authority telehealth facilities. Overall, participants expressed satisfaction with telemedicine; satisfaction was higher for support persons/patient and administrators than for assessors.

\section{Qualitative findings}

The following dimensions provide a summary of the qualitative findings. Additional representative quotes are presented in Table 5 .

\section{Acceptability}

The support persons and the patient thought that MAiD assessment via telemedicine was acceptable. Qualifiers included "easier," "convenient," "natural," "patient centred," "adequate," "personal," "helpful," "fantastic" and "positive." Assessors also expressed positive comments regarding telemedicine acceptability, despite conveying overall more reservation. One assessor stated that "the

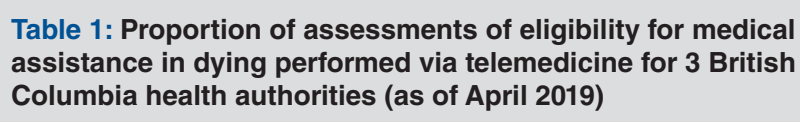

\begin{tabular}{|lcc|}
\hline Health authority & $\begin{array}{c}\text { Total no. of MAiD } \\
\text { requests }\end{array}$ & $\begin{array}{c}\text { No. (\%) of MAiD } \\
\text { assessments by } \\
\text { telemedicine }\end{array}$ \\
\hline $\begin{array}{l}\text { Fraser Health } \\
\text { Authority }\end{array}$ & 621 & $2(0.3)$ \\
\hline $\begin{array}{l}\text { Vancouver Coastal } \\
\text { Health }\end{array}$ & $51(5.7)$ \\
\hline $\begin{array}{l}\text { Vancouver Island } \\
\text { Health Authority* }\end{array}$ & NA $(6.2)$ \\
\hline $\begin{array}{l}\text { Note: MAiD = medical assistance in dying, NA = not available. } \\
\text { *This health authority could provide only the number of medically assisted } \\
\text { deaths (839); it did not have robust data on the total number of MAiD requests at } \\
\text { the time of the survey. }\end{array}$ \\
\hline
\end{tabular}




\begin{tabular}{|c|c|c|c|c|}
\hline \multirow[b]{2}{*}{ Group } & \multicolumn{4}{|c|}{ Characteristic } \\
\hline & Age, yr & Sex & Location & Diagnosis \\
\hline \multicolumn{5}{|c|}{$\begin{array}{l}\text { Support } \\
\text { persons/patient }\end{array}$} \\
\hline A & NA & Female & $\begin{array}{l}\text { Out of } \\
\text { province }\end{array}$ & Conversion disorder \\
\hline B & $71-80$ & Male & Urban & Parkinson disease \\
\hline C & $61-70$ & Female & Rural & Cancer \\
\hline $\mathrm{D}$ & $61-70$ & Female & Urban & NA \\
\hline E & $61-70$ & Female & Urban & Pulmonary fibrosis \\
\hline $\mathrm{F}$ & $41-50$ & Female & Rural & Cancer \\
\hline $\mathrm{G}$ & $71-80$ & Male & Urban & Multiple sclerosis \\
\hline $\mathrm{H}$ & $61-70$ & Male & Rural & $\begin{array}{l}\text { Borderline personality } \\
\text { disorder, chronic asthma }\end{array}$ \\
\hline Assessors & & & & $\begin{array}{l}\text { No. of MAiD eligibility } \\
\text { assessments performed } \\
\text { with telemedicine }\end{array}$ \\
\hline A & $61-70$ & Female & Urban & 5 \\
\hline B & $21-30$ & Male & Urban & 3 \\
\hline C & $51-60$ & Male & Rural & $\sim 10$ \\
\hline D & $41-50$ & Female & Urban & $\sim 6$ \\
\hline$E$ & $41-50$ & Female & Rural & 5 \\
\hline$F$ & $51-60$ & Female & Urban & $10-15$ \\
\hline G & $61-70$ & Male & Rural & 4 or 5 \\
\hline $\mathrm{H}$ & $31-40$ & Female & Urban & 1 \\
\hline \multicolumn{5}{|c|}{ Administrators } \\
\hline A & $41-50$ & Female & - & - \\
\hline B & $51-60$ & Female & - & - \\
\hline C & $41-50$ & Female & - & - \\
\hline D & $31-40$ & Female & - & - \\
\hline$E$ & NA & Male & - & - \\
\hline
\end{tabular}

ability to touch, or the ability to move or see how [the patient is] moving is more difficult and limited, so empathy is reduced" (assessor F). Similarly, another assessor reported, "It's not as warm and fuzzy as in person, but all the in person are not necessarily warm and fuzzy, either" (assessor G). Several participants thought that the context inherent to telemedicine assessments was not as rich or complete: "With telemedicine, I really just focus in on what their experience is with their illness or with their disease and less about them as a person, so I lose that aspect of knowing them" (assessor F). The administrators who acted as witnesses felt that their presence added a human touch to the consultation: "Sometimes I have been able to interpret what a physician has said on the phone ... or also follow up with the patient about some of the conversations that happened on the phone" (administrator A).

\section{Appropriateness}

The support persons and the patient thought that using telemedicine was appropriate for their specific situation. For assessors and administrators, the appropriateness of telemedicine related to specific patient characteristics: "The patient needs to be able to use the technology appropriately, to be seen, to be visualized, to be heard, to make [him- or herself] understood" (assessor D). Another assessor stated, "In somebody who is alert and able to ... very quickly and clearly provide consent, then I think telemedicine is fine" (assessor E). Two assessors expressed concerns about assessing frail patients via telemedicine.

\section{Accessibility}

Participants thought that telemedicine facilitated access to MAiD assessments for their loved ones because of their limited physical capacity: "I couldn't have gotten him in the car, 


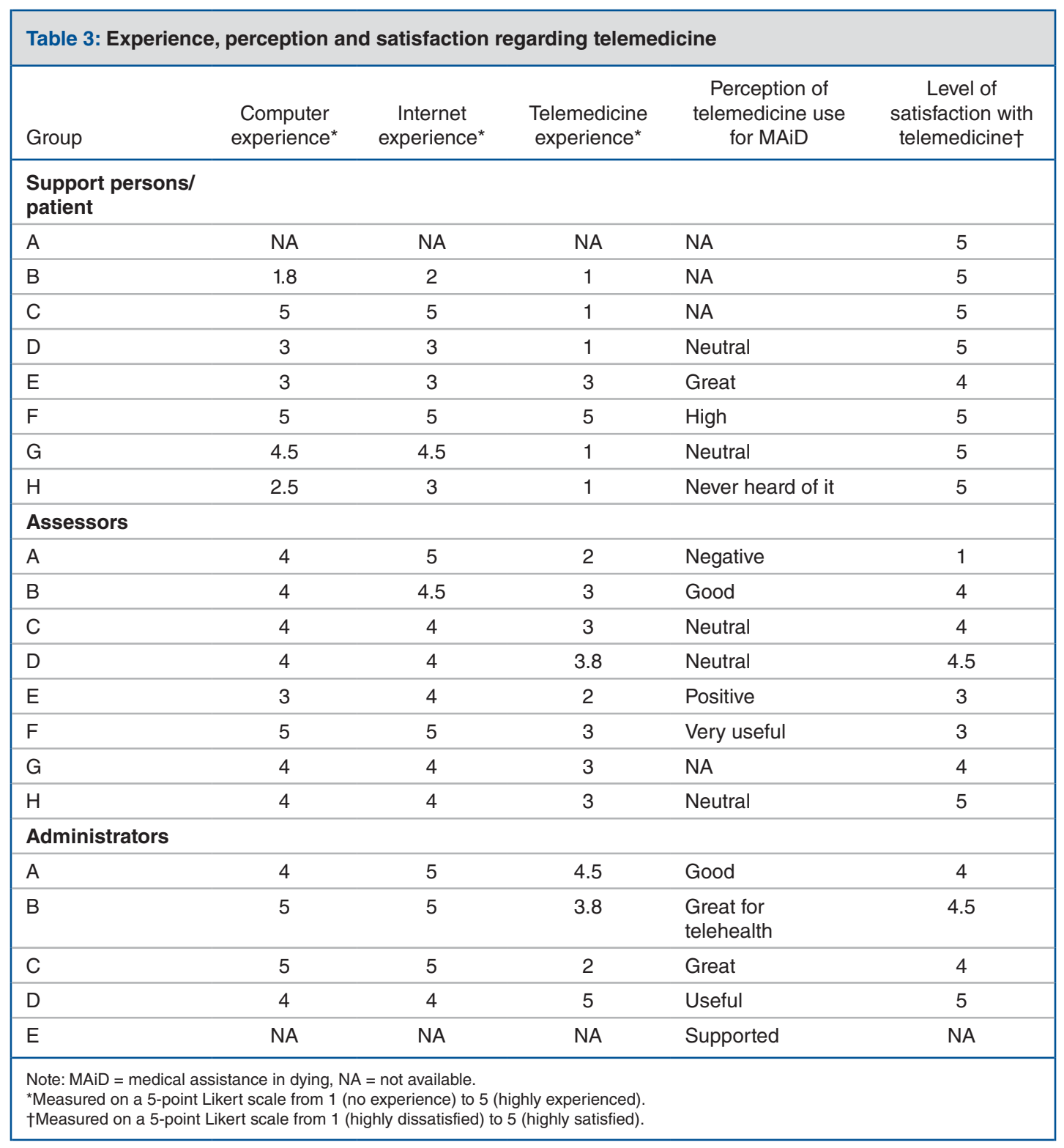

gotten him onto the ferry ... that would have been really, really sad to have to do that" (support person C). In 2 instances, support persons believed that having the telemedicine option allowed access to MAiD because their loved ones were not able to travel for an in-person assessment: "It was her only way to find a doctor to do this, it was a miracle that Skype was available, it was wonderful" (support person A). Some assessors described telemedicine as facilitating MAiD assessments because of factors such as distance or underserviced areas. Two administrators thought that telemedicine increased access in a timely manner for the patients, highlighting that, even in larger population settings, access to inperson MAiD assessment was sometimes challenging.

\section{Effectiveness}

The support persons and patient thought that telemedicine was an effective way to conduct a MAiD assessment given their circumstances. Comments included "In that situation, it's whatever works ... and it worked" (support person C) and "It served the purpose that we were trying to achieve" (support person B). Most assessors had similar thoughts, concluding that they were able to reach their goals despite limitations inherent to telemedicine: "It gets the job done ... and ... at the end it is what it is right" (assessor G) and "It's [not] as good as it can be in person but still good enough for me to do this work" (assessor D). Some assessors felt the need to expedite MAiD assessments via telemedicine owing to associated time limitations.

\section{Safety}

The support persons and patient did not express concerns related to safety in the context of telemedicine. For assessors, the recurring themes were privacy and confidentiality, especially when using their own device and software. Three 


\begin{tabular}{|c|c|c|c|}
\hline Group & Device & Software & Location \\
\hline \multicolumn{4}{|c|}{ Assessors } \\
\hline A & iPhone & FaceTime & Home \\
\hline B & iPhone & FaceTime & Home or hospital \\
\hline C & iPhone & FaceTime & Home \\
\hline D & $\begin{array}{l}\text { Laptop, telehealth, }{ }^{*} \\
\text { telephone }\end{array}$ & Mainly Skype & Home \\
\hline$E$ & $\begin{array}{l}\text { Computer, telephone, } \\
\text { telehealth }\end{array}$ & $\begin{array}{l}\text { Telehealth, FaceTime, } \\
\text { Skype }\end{array}$ & $\begin{array}{l}\text { Home or } \\
\text { telehealth }\end{array}$ \\
\hline $\mathrm{F}$ & Various & Various & $\begin{array}{l}\text { Home or } \\
\text { telehealth }\end{array}$ \\
\hline G & Telehealth & Telehealth & Telehealth \\
\hline$E$ & iPhone & FaceTime & Home \\
\hline \multicolumn{4}{|c|}{$\begin{array}{l}\text { Support persons/ } \\
\text { patient }\end{array}$} \\
\hline A & Computer & Skype or FaceTime & Home \\
\hline B & iPad & FaceTime & Home \\
\hline C & Computer & FaceTime & Home \\
\hline D & iPhone & FaceTime or Skype & Home \\
\hline$E$ & iPad & Skype & Home \\
\hline $\mathrm{F}$ & iPhone & FaceTime & Home \\
\hline G & Computer & Skype & Home \\
\hline$E$ & Computer & Skype & Home \\
\hline \multicolumn{4}{|c|}{$\begin{array}{l}\text { Note: MAiD = medical assistance in dying. } \\
\text { "To achieve MAiD eligibility assessments via telemedicine, MAiD assessors and patients in British Columbia have been } \\
\text { using the health authorities' teleconference sites, commonly known as telehealth sites. These sites can be accessed at } \\
\text { various locations within a health authority and comprise a television screen or computer monitor, video camera and } \\
\text { microphone, operating over a secure network. Assessors and patients have also been using their own device and } \\
\text { software to perform or obtain their consultation remotely. }\end{array}$} \\
\hline
\end{tabular}

administrators confirmed that their health authority recommended the use of a consent form for an assessment in which software that is not considered secure was used.

Three assessors doubted that the witness requirement had a meaningful impact on preventing coercion and felt that having a stranger in the room during the assessment was at times intrusive.

\section{Efficiency}

Support persons were adamant that telemedicine saved substantial travel time. One reported that telemedicine was also cost saving, given the travel cost of an in-person assessment. The assessors agreed that telemedicine assessments overall required less time, avoiding long-distance travel to assess a patient: "It allows the process in a timely fashion with ... efficient utilization of physician and patient resources in the sense that it takes the travel away" (assessor G). Two administrators and 1 assessor thought that planning for telemedicine took longer than planning for an in-person assessment owing to the need to find and organize a witness. Several participants acknowledged that using telemedicine was cost saving from a system perspective, as the health authority did not have to reimburse travel fees for in-person assessments. Technologic issues rarely impeded the telemedicine consultations, but several assessors mentioned difficulty conducting an assessment when the patient had to be lying flat in bed: "The most important thing ... is that I can see the patient, and sometimes it's difficult if [he or she is] lying flat or — it's quite difficult for [the patient] to see me, but I'm able to see [the patient]" (assessor C). Several participants thought that MAiD coordinators were instrumental in providing assistance and support for telemedicine.

\section{Equity}

Several participants pointed out that telemedicine allowed equitable access to MAiD assessment. One assessor noted, "Telemedicine can be the difference for allowing access to this care for certain people in certain areas" (assessor D).

\section{Interpretation}

Findings from this research show that quality of care can be achieved through MAiD eligibility assessments via telemedicine for specific situations and patients. We found that the BC 
Table 5 (part 1 of 2): Representative quotes for each dimension of the BC Health Quality Matrix

\begin{tabular}{|c|c|}
\hline Dimension & Representative quote \\
\hline \multirow[t]{7}{*}{ Acceptability } & $\begin{array}{l}\text { By the time ... a patient has been through going to the doctor, going to the hospital, getting } \\
\text { blood work, getting this test and that test, it's nice to be able to just [lie] back in the comfort of } \\
\text { your own home and have someone come to you for a change. That what he [patient] felt like. } \\
\text { He just felt "Oh, I don't want to go see another doctor and do that travel. I just want to stay } \\
\text { here." (support person F) }\end{array}$ \\
\hline & $\begin{array}{l}\text { I try very hard during a telemedicine [session] to get past the fact that we're not actually } \\
\text { physically in each other's presence, so I sort of act more. I'm really more active. I'm much more } \\
\ldots \text { demonstrative with my arms and so forth when I'm talking. I'm even doing it now while we're } \\
\text { talking [laughter] to really sort of try and engage. So, I do deliberately try and make it not just a } \\
\text { telephone call with pictures. (assessor C) }\end{array}$ \\
\hline & $\begin{array}{l}\text { It's pretty good, actually. It allows me to - obviously it's slightly easier if I was in the room with } \\
\text { the patient and any family member ... they decided to bring, I can more easily detect the fact } \\
\text { that a family member wants to add something, but I don't find it obstructs. I can ask ... "Is there } \\
\text { anybody else who wants to add anything at this point?" ... It requires a slightly different } \\
\text { technique, but it doesn't obstruct. (assessor C) }\end{array}$ \\
\hline & $\begin{array}{l}\text { If I hadn't been there, she just would have been in a room by herself and ... I said "We've got } \\
\text { some water" and "Are you anxious?" and ... I just tried to put her at ease ... and then afterwards } \\
\text { I think she just ... to have a human there to kind of debrief and breathe with and ... because } \\
\text { they have a lot of anxiety, they feel like it's a test ... and it is, they are being tested for eligibility } \\
\text { and ... whether they meet the criteria. So ... the witness role is there for safety, but I think it can } \\
\text { also add a human support element, before and after. (administrator B) }\end{array}$ \\
\hline & $\begin{array}{l}\text { I think you establish more rapport when you go to meet someone in their home and you have } \\
\text { more time for small talk, and, as we sort of mentioned, that nonverbal communication and } \\
\text { speaking with their family, and I think you just have more time and space with an in-person } \\
\text { consult than you do over telemedicine. (assessor B) }\end{array}$ \\
\hline & $\begin{array}{l}\text { I usually sit fairly close to the patient, so maybe there's a little bit of ... maybe l'm sort of doing } \\
\text { that usual piece on behalf of the assessor in regard to ... touching the patient, especially if [the } \\
\text { patient has] expressed something really difficult ... or [is] in tears. (administrator A) }\end{array}$ \\
\hline & $\begin{array}{l}\text { Eye contact is a bit difficult ... because sometimes the way that cameras are tilted or the way } \\
\text { that people hold their hands because they are kind of looking ... they are looking at you, but } \\
\text { they are looking at a void, too, and vice versa, I think it applies to both ends ... and so ... it } \\
\text { takes maybe a touch more effort than if you were sitting across ... from each other. } \\
\text { (assessor G) }\end{array}$ \\
\hline \multirow[t]{2}{*}{ Appropriateness } & $\begin{array}{l}\text { Particularly when people are old and frail, the difficulty that they had was not being able to hear } \\
\text { me well on the other end. Whereas when I'm in front of the other person, I can lean over to the } \\
\text { correct ear that [the person] can hear best out of, or be more expressive in ... body language } \\
\ldots \text { but that's not possible on telemedicine. (assessor F) }\end{array}$ \\
\hline & $\begin{array}{l}\text { Obviously she [assessor] can't ... physically observe the swelling in my wife's legs, for example } \\
\ldots \text { but as an initial consultation, her ability to do an assessment of [my wife's] competence and } \\
\text { her true desire and all of that, it was a perfectly legitimate tool. (support person G) }\end{array}$ \\
\hline \multirow[t]{2}{*}{ Accessibility } & $\begin{array}{l}\text { [The patient] wouldn't have been able to do it otherwise, I don't think, because he would have } \\
\text { had to travel to Vancouver, and by the time the [general practitioner] got the paperwork and } \\
\text { everything going ... we had to be at a point where it's imminent, so to then have him loaded up } \\
\text { and taken to either [Vancouver Island] or Vancouver would have been an ordeal for him. It } \\
\text { would have been exhausting. (support person F) }\end{array}$ \\
\hline & $\begin{array}{l}\text { I think that the access for the patient, in the setting that [the patient] chooses is ... a real ... } \\
\text { benefit, and also ... minimizes the disruption further ... so that [the patient] doesn't need to } \\
\text { travel to a hospital setting, for example, and, similarly, it's more accessible for the assessor, } \\
\text { who also doesn't need to be in a particular place. (administrator E) }\end{array}$ \\
\hline
\end{tabular}

Health Quality Matrix was a useful framework to analyze quality of care in this situation. Overall, participants expressed satisfaction; satisfaction was higher for support persons, the patient and administrators than for assessors.

Acceptability was very high among support persons and the patient; this is an essential finding given the importance of a patient-centred practice. These results are similar to those of previous research on telemedicine consultations, ${ }^{15,16}$ which also showed high acceptability among patients. In the current study, the assessors expressed limitations in their ability to be empathetic via telemedicine and described challenges with the nonverbal communication and with losing contextual factors, which likely contributed to their lower level of satisfaction. This feeling was also discussed in research on providers' perspective on telemedicine and abortion; inability to provide physical comfort to patients was reported as a limitation for the providers. ${ }^{17}$

Patient characteristics emerged as the main factor influencing telemedicine appropriateness. Most participants thought 
Table 5 (part 2 of 2): Representative quotes for each dimension of the BC Health Quality Matrix

Dimension Representative quote

Effectiveness

I find it's shorter than with the face-to-face contacts because there aren't as many cues to me to ask about further life issues or questions about knowing that person, so I find it restrictive in that sense. (assessor F)

Sometimes patients are quite weak just because they're tired, and whereas in a face-to-face [session] you can sort of manage that, [with] telemedicine, because there's sort of a slight time imperative, or you can't pause in the same way, I therefore may sometimes be a little less - I may explore threads or avenues less than I would ... face-to-face. (assessor C)

There's kind of pressure, because it takes so much - it takes resources to coordinate telemedicine in terms of having someone available on the other end, you feel like you really want to be thorough and get the entire assessment done in one chunk, whereas [with] in-person assessments, l've gone back for some challenging cases 3 or 4 times, and you can spend 15 minutes with someone who has a short attention span or [less] energy. You can say, "Okay, that's enough for today, we'll come back another time and pick up where we left off," but with telemedicine there's kind of pressure to wrap it up and everything done in 1 session. (assessor B)

Safety It seems ad hoc to use my personal device on my home Wi-Fi network, and I guess I'm not a tech expert, but ... I wonder if there would ever be any security issues over network security or anything like that. (assessor B)

I think that most of the people who are making this request for medical assistance in dying ... [aren't] worried about Russian hackers hearing their conversation, so this security - what are we talking about? That their family finds out? That's irrelevant [with] telemedicine. Are we worried that some hacker on the Internet ... can find out? I'm not sure that patients care, so I'm not exactly sure what the security risk is, so I'm not too concerned about it. But from a technological point of view, yeah, I don't think they're very safe, but I don't think anyone minds. (assessor D)

Ultimately it's up to the patient, if the patient is comfortable with having a FaceTime or Skype assessment ... then it's up to [the patient].... I don't think that I should impose ... again, this is sort of coming back to ... patient autonomy, so if the patient is aware that there are potential risks ... then [the patient has] the right to say no to a telemedicine assessment, but, again, I would put it on to the patient to decide if [he or she is] comfortable with a telemedicine assessment or not. (administrator $\mathrm{A}$ )

Because patients are fully capable of exercising their own rights and also exercising their information right, it is advantageous that they are able to make use of more portable and even more accessible telemedicine services like FaceTime and Skype ... which is not the case for more traditional, structural telemedicine services as one might find ... between hospitals ... having to go into an hospital to have that telemedicine service. ... So I think that ... we've pushed some boundaries about ... telemedicine, and I think that's been helpful. (administrator E) I see why it needs to be there so that we can ensure that someone is not under duress, but I do find it a bit of an invasion of ... privacy, so I'm mixed about that requirement [for a witness]. I'm not sure that it actually helps us decide that there is no duress. I think that, if there's duress, that witness could be part of the whole thing, so I don't know that it actually is protective. I find it more of an invasion than a protection. (assessor D)

The witness has to be a health professional, so I don't have any problems at all with the idea of that person being present. They very often, in the communities I deal with... know the patient, so it's very often somebody who has had professional interactions with the patient, and I don't find that a problem. In any case, I understand the need for it, and it's rather like a chaperone, if I'm doing an examination [for] a female patient, then I have a chaperone always. I don't really have any choice in that because it's for my protection. So, in this case, although the patient may not feel that [he or she] needs the protection of a health professional, I fully understand it. (assessor C)

Efficiency It's possible they could have flown me out to do an assessment one day and then the provision the next day, it probably still could have happened, but it certainly made things a lot easier to have telemedicine available to do the initial assessment in that case. (assessor B)

The other cost is trying to track down a nurse or another medical professional to try and be with [the patient].... That is a huge cost of phoning around to see if someone can be on the other end. ... It's really the biggest barrier for me. (assessor F)

Equity In the early days, telemedicine was especially important for areas that were underserviced, and that continues in many places in this country where there are not assessors and providers. And telemedicine can be the difference for allowing access to this care for certain people in certain areas, and so I think it's an incredibly powerful tool to allow access. (assessor D) 
that, for a telemedicine assessment to be appropriate, the patient needed to be able to hear, see and speak, or communicate effectively and be proficient with the selected technology. Similar patient characteristics have been reported as being appropriate for telemedicine assessment in a previous study on telemedicine and abortion. ${ }^{17}$ Several assessors noted that frail people might be difficult to assess via telemedicine owing to limited or fluctuating capacity to meet those criteria, an important consideration given the notable proportion of frail patients requesting MAiD. ${ }^{5}$ The greatest degree of unanimity was observed for the accessibility dimension: participants expressed that telemedicine facilitated access to the assessment and even allowed access for some patients. Research on abortion $^{18}$ and palliative care ${ }^{16}$ assessments via telemedicine also showed increased access to services when telemedicine was available.

Overall, participants agreed that using telemedicine was effective. The patient and support persons had no concerns about safety. Different perceptions on privacy regulations were voiced by assessors, which highlights the need to clarify standards of practice in this regard. Several participants agreed that telemedicine was efficient but that organizing a witness was a barrier to efficiency. The importance of the MAiD coordinators in providing operational support for the telemedicine consultation was emphasized, which shows that this recent policy was a positive initiative for the MAiD program in BC. Other studies showed increased efficiency with telemedicine, ${ }^{19-21}$ such as reduced overall cost for women for abortion consultation via telemedicine. ${ }^{19}$

As of April 2019, the use of telemedicine for MAiD eligibility assessments was relatively low in BC. Assessing and promoting the integration of a patient-centred virtual health model of service for the MAiD program in BC, with standard processes for access, consent and secure online platform, would be useful in harmonizing telemedicine practices and facilitating access to the service. We recommend clear mechanisms, such as consent forms, and communication between assessors and administrators to implement those mechanisms in order to enforce informed consent and protect patients. We need to know more about how patients and support persons perceive the witness requirement for telemedicine assessments. Another important area of research is specific outcomes related to telemedicine assessments that were outside the scope of this study. In particular, outcomes related to effectiveness, aside from participant satisfaction, should be investigated. Future research should also include the First Nations Health Authority given the remote or rural nature of some First Nations communities.

\section{Limitations}

One limitation of this study is the small sample; data saturation was reached for some aspects in some groups, but not all. The sample was obtained with contacts from a single clinic, which increases the possibility of selection bias; however, participants came from various rural and urban areas of BC, which increases external validity. The interview guide was not validated with a wide sample of respondents. It is possible that the questions were not interpreted properly by the interviewees or did not provide a comprehensive approach to the topic. We used a Likert scale for specific questions such as participants' satisfaction with telemedicine; answers to these questions should be interpreted with caution, as this method does not provide optimal internal consistency. We do not have data for the people who did not use telemedicine, apart from information on proportion. The perspective of support persons/patients regarding the witness requirement was not obtained for this research. Finally, this research did not include perspectives of First Nations people.

\section{Conclusion}

This research showed that telemedicine can be used for MAiD eligibility assessments in a manner that is acceptable and effective for patients and assessors while improving efficiency of the program. Telemedicine has the potential to expand access to MAiD; this is of particular relevance given BC's geographic context, assessor shortage and patients' limited physical capacity to travel. Careful consideration of the risks and benefits of a MAiD eligibility assessment via telemedicine, on a case-by-case basis, is recommended to promote quality of care.

\section{References}

1. Medical assistance in dying. Victoria: British Columbia Ministry of Health. Available: www2.gov.bc.ca/gov/content/health/accessing-health-care/home -community-care/care-options-and-cost/end-of-life-care/medical-assistance-in -dying (accessed 2019 Feb. 21)

2. Fourth interim report on medical assistance in dying in Canada. Ottawa: Health Canada; 2019. Available: www.canada.ca/en/health-canada/services/publications/ health-system-services/medical-assistance-dying-interim-report-april-2019.html (accessed 2019 May 2).

3. Robertson WD, Pewarchuk JA, Reggler J, et al. Case review of medically assisted deaths on Vancouver Island. BCM7 2017;59:305-9.

4. Schiller CJ. Medical assistance in dying in Canada: focus on rural communities. 7 Nurse Pract 2017;13:628-34.

5. Robertson WD, Beuthin R. A review of medical assistance in dying on Vancouver Island: the first two years - Fuly 2016-fuly 2018. Victoria: Island Health; 2018. Available: www.islandhealth.ca/sites/default/files/2018-10/MAiD-Report-2016 -2018.pdf (accessed 2019 Mar. 7).

6. Medical assistance in dying. Ottawa: Health Canada; 2019 Apr. 25. Available: www.canada.ca/en/health-canada/services/medical-assistance-dying.html (accessed 2019 Feb. 21).

7. Practice standards: medical assistance in dying. Vancouver: College of Physicians and Surgeons of British Columbia; revised 2019 June 20. Available: www.cpsbc.ca/files/pdf/PSG-Medical-Assistance-in-Dying.pdf (accessed 2019 Feb. 21)

8. Terekhova E, Tabassi HR, Gabriel P, et al. Telemedicine in primary care: Who are the current users in British Columbia? BCMF 2017;59:264-8.

9. Chen J, Jin W, Zhang XX, et al. Telerehabilitation approaches for stroke patients: systematic review and meta-analysis of randomized controlled trials. $\mathcal{F}$ Stroke Cerebrovasc Dis 2015;24:2660-8.

10. Rasmussen OW, Lauszus FF, Loekke M. Telemedicine compared with standard care in type 2 diabetes mellitus: a randomized trial in an outpatient clinic. 7 Telemed Telecare 2016;22:363-8.

11. Health Quality Matrix BC. Vancouver: BC Patient Safety \& Quality Council; 2017. Available: https://staging.bcpsqc.ca/resource/bc-health-quality-matrix/ (accessed 2019 Feb. 21).

12. Setting priorities for the B.C. health system. Victoria: BC Ministry of Health 2014. Available: www.health.gov.bc.ca/library/publications/year/2014/Setting -priorities-BC-Health-Feb14.pdf (accessed 2019 Aug. 25).

13. DePoy E, Gitlin LN. Introduction to research: understanding and applying multiple strategies. 4th ed. Toronto: Elsevier Canada; 2010.

14. Our vision and values. Vancouver: BC Patient Safety \& Quality Council. Available: https://bcpsqc.ca/about-the-council/our-vision-and-values/ (accessed 2019 Feb. 21)

15. Grindlay K, Lane K, Grossman D. Women's and providers' experiences with medical abortion provided through telemedicine: a qualitative study. Womens Health Issues 2013;23:e117-22. 
16. Rogante M, Giacomozzi C, Griogioni M, et al. Telemedicine in palliative care: a review of systematic reviews. Ann Ist Super Sanita 2016;52: 434-42.

17. Grindlay K, Grossman D. Telemedicine provision of medical abortion in Alaska: through the provider's lens. 7 Telemed Telecare 2017;23:680-5.

18. Fok WK, Mark A. Abortion through telemedicine. Curr Opin Obstet Gynecol 2018;30:394-9.

19. Hyland P, Raymond EG, Chong E. A direct-to-patient telemedicine abortion service in Australia: retrospective analysis of the first 18 months. Aust N Z J Obstet Gynaecol 2018;58:335-40.

20. Oliver DP, Demiris G, Wittenberg-Lyles E, et al. A systematic review of the evidence base for telehospice. Telemed f E Health 2012;18:38-47.

21. Capurro D, Ganzinger M, Perez-Lu J, et al. Effectiveness of eHealth interventions and information needs in palliative care: a systematic literature review. 7 Med Internet Res 2014;16:e72.
Affiliations: School of Public Health (Dion) and Department of Family Practice (Wiebe), University of British Columbia, Vancouver, BC; London School of Hygiene and Tropical Medicine (Kelly), University of London, London, UK

Contributors: Stephanie Dion and Ellen Wiebe conceived the study. All of the authors contributed to the study design, analyzed and interpreted the data, drafted the manuscript and revised it critically for important intellectual content, approved the final version to be published and agreed to be accountable for all aspects of the work.

Supplemental information: For reviewer comments and the original submission of this manuscript, please see www.cmajopen.ca/content/7/4/ E721/suppl/DC1. 